\title{
Perceptions and correspondence of climate change beliefs and behavior among romantic couples
}

\author{
Matthew H. Goldberg ${ }^{1}$, Cheryl L. Carmichael ${ }^{2,3}$, Karine Lacroix ${ }^{1}$, \\ Abel Gustafson ${ }^{4}$, Seth A. Rosenthal ${ }^{1}$, and Anthony Leiserowitz ${ }^{1}$ \\ ${ }^{1}$ Yale Program on Climate Change Communication, Yale University \\ ${ }^{2}$ Department of Psychology, Graduate Center, City University of New York \\ ${ }^{3}$ Department of Psychology, Brooklyn College, City University of New York \\ ${ }^{4}$ Department of Communication, University of Cincinnati
}

Romantic partners influence each other's beliefs and behaviors. However, little is known about the dynamics of climate change beliefs and behaviors within romantic couples. We surveyed 758 romantic couples ( $N=1,516$ individuals) to investigate (a) correspondence between partners' climate change beliefs/behaviors, (b) accuracy and bias in people's perceptions of their partner's beliefs/behaviors, (c) whether a person's perceptions of their partner's beliefs/behaviors are more strongly predicted by that partner's actual beliefs/behaviors or by projections of one's own beliefs/behaviors, and (d) how perceptual accuracy varies across moderating variables such as frequency of discussion about global warming. We find that climate change beliefs and behaviors often differ between romantic partners. Moreover, people's perceptions of their partner's beliefs/behaviors are predicted by their own beliefs and behaviors (assumed similarity), independently from the predictive effect of their partner's actual beliefs and behaviors (accuracy). We identify opportunities for future research on relationship-based climate change interventions.

Keywords: climate change, global warming, climate change communication, romantic relationship, pro-environmental behavior

Public and political will are needed to address climate change (Leiserowitz, 2019). Effective climate change communication is essential to serving this goal-it can facilitate change by building public support for pro-climate policies and behaviors and by inspiring collective action (Ockwell et al., 2009).

Social norms are an effective means of fostering pro-climate beliefs and behavior (Bergquist et al., 2019; Jachimowicz et al., 2018). One popular and effective communication strategy is to identify people who underestimate public support for a given policy or behavior in their country or local area, and then correct their misperception with accurate information, with the goal of promoting more pro-climate beliefs, behavior, and policy support (e.g., Mildenberger \& Tingley, 2019). One important drawback of common norm interventions, however, is that the referent group is often a large, impersonal group (e.g., one's country) that might not be nearly as influential as close social network members (Goldberg, Gustafson, \& van der Linden, 2020).

Correspondence concerning this paper should be addressed to Matthew H. Goldberg, Yale Program on Climate Change Communication, Yale University. Email: matthew.goldberg@yale.edu. Thank you to Brenton Wiernik for this wonderful preprint template, the source of which can be found at doi.org/10.17605/OSF.IO/HSV6A. 
Close others, on the other hand, can be uniquely influential. As intimate relationships develop and closeness increases, partners' individual identities fuse (Walsh \& Neff, 2018). According to theoretical models of cognitive interdependence, mental representations of close others become internalized, and their influence on one's thoughts, feelings, and behaviors becomes automatic and ubiquitous (Agnew, Van Lange, Rusbult, \& Langston, 1998; Smith \& Mackie, 2016). For example, people are particularly likely to follow the norms of their social circle regarding flu vaccines (de Bruin, Parker, Galesic, \& Vardavas, 2019). Of the numerous types of close relationships, romantic relationships tend to be particularly influential and important compared to other types of close relationships (Reis, Clark, \& Holmes, 2004; Rusbult \& Van Lange, 2003), which is evident in the domain of health behavior (Berli, Bolger, Shrout, Stadler, \& Scholz, 2018; Lewis \& Butterfield, 2007). For example, a large-scale study of the social network dynamics of cigarette smoking found that, if a spouse quit smoking, a person's chances of smoking decreased by $67 \%$, whereas if a sibling quit smoking, the person's chances of smoking decreased by only 25\% (Christakis \& Fowler, 2008). This research highlights the importance of romantic partners in understanding people's beliefs and behaviors.

In order to understand whether social influence among close others (i.e., romantic partners) is a plausible approach to increasing people's pro-climate beliefs and behaviors, we first need to understand whether the discrepancies between relationship partners' climate beliefs/behavior are large enough to leave room for social influence. Thus, we first examine correspondence of climate beliefs and behaviors among romantic partners.

\section{Correspondence}

There are competing perspectives regarding whether leveraging social influence in romantic relationships might shift opinions on climate change. For example, as close social network members, romantic partners might have more potential for social influence because of access: they are trusted, nearby, and in position to influence (Goldberg et al., 2020). However, the issue of selection is a potential drawback: people are often drawn to and surrounded by people that are similar to themselves (Byrne, 1961; Rossignac-Milon, Bolger, Zee, Boothby, \& Higgins, 2020).

Moreover, partners may become more similar over time as they grow closer and expand their self-view to include a romantic partner's characteristics (Aron, Aron, Tudor, \& Nelson, 1991). However, although romantic partners often have similar beliefs across a range of topics, they also change their beliefs independently of each other (Hammond \& Sibley, 2022). This highlights the need to understand the degree to which romantic partners differ in their climate beliefs and behaviors, and whether partner-based interventions are a promising avenue for fostering stronger pro-climate beliefs and behavior.

If there are only small discrepancies between partners' beliefs or behaviors, this allows little opportunity for one member of the relationship to influence the views of the other. In contrast, lower levels of correspondence between romantic couples' climate beliefs or behavior could provide more opportunities for social influence interventions. Thus, in this study, we first seek to answer the question:

RQ1: How similar are the climate change beliefs and behaviors ${ }^{1}$ of romantic partners (i.e., correspondence)?

\section{Accuracy and Bias}

\footnotetext{
${ }^{1}$ There may be situations and contexts where beliefs and behavior operate differently from each other. However, we mention beliefs and behavior at the same time because our hypotheses for each are largely the same, and for ease and clarity of communication.
} 
Beyond the question of how much partners' climate beliefs and behaviors correspond, it is also essential to examine the accuracy and bias in partners' perceptions of each other's climate beliefs and behaviors. It is common to find that people are inaccurate in estimating the proportion of large groups of people (e.g., the general population, members of a political party) who believe climate change is happening, are worried about it, or support policies to mitigate it (Abeles et al., 2019; Ballew et al., 2020; Mildenberger \& Tingley, 2019). However, it is unclear whether this applies to people in close relationships, such as romantic partners. For example, given the special level of closeness in a romantic relationship, it is reasonable to expect that partners can accurately estimate what their partner believes and how they behave with regard to climate change. However, studies often find that, even though most people report being worried about climate change, most people rarely or never talk about it with close others (Leiserowitz et al., 2021) — potentially resulting in inaccurate perceptions of what one's partner believes.

We draw on the Truth and Bias model (Stern \& West, 2018; Stern, West, \& Schoenthaler, 2013; West \& Kenny, 2011) to understand how people perceive their partner's climate beliefs and behavior. According to the model, judgment of another person's beliefs (or thoughts, or behaviors) is derived from the truth (the other person's actual beliefs) and from bias (any other factors that guide judgements besides the truth). We refer to truth judgments as accuracy because they reflect the extent to which one's perceptions of their partner match reality.

One key biasing factor is one's own beliefs. For example, people often use their own beliefs/behavior as a heuristic for estimating what other people believe (Marks \& Miller, 1987; Ross et al., 1977; West \& Kenny, 2011). We refer to this as assumed similarity. This assumed similarity is a common source of bias in judgements about romantic partners (Stern \& West, 2018). For example, people who are worried about climate change would be expected to think that other people around them are also worried, whereas people who are not worried about it themselves would be more likely to think that others are also not worried. This general phenomenon has been observed for a wide range of issues, including climate change (Ballew et al., 2020).

An extensive literature on accuracy and bias in romantic relationships reflects how common it is for partners to simultaneously be both biased and accurate in their judgments of each other's traits, beliefs, behaviors, memories, and more (Fletcher, 2015; Fletcher \& Kerr, 2010; Gagne \& Lydon, 2004). A review revealed a robust accuracy effect across nearly 100 studies, and a small but consistent bias effect across almost 50 studies (Fletcher \& Kerr, 2010). In a study similar to ours, a person's perception of the support they received from their partner was predicted in part by the support their partner reported providing (accuracy) and the support they themselves had provided to their partner (bias, or assumed similarity; Bar-Kalifa, Rafaeli, \& Sened, 2016). Accordingly, in the current study, we examine:

RQ2: How accurate and biased are people at estimating what their partner believes and how they behave with regard to climate change?

RQ3: Are people's perceptions of their partner's climate beliefs and behavior more strongly predicted by their partner's actual beliefs and behaviors (i.e., accuracy) or by projections of their own beliefs and behaviors (i.e., biased via assumed similarity)?

We did not form hypotheses about the relative strength of accuracy or assumed similarity effects. If, for example, perceptions of a partner's beliefs were shaped exclusively by the partner's actual beliefs (i.e., accuracy), then the role of assumed similarity would be negligible. Likewise, if understanding of a partner's beliefs were shaped exclusively by projection of one's own beliefs (i.e., assumed similarity), the role of accuracy would be negligible. The literature leaves unclear 
whether accuracy or assumed similarity should predominate for this topic and context, but the Truth and Bias model makes clear that people's perceptions of their partners are often shaped by a combination of accuracy and bias (Stern \& West, 2018; Stern, West, \& Schoenthaler, 2013; West $\&$ Kenny, 2011). Thus, consistent with this model, we hypothesized:

H1: People's perceptions of their partner's beliefs will be predicted by the partner's actual beliefs (i.e., accuracy) and one's own beliefs (i.e., assumed similarity).

\section{Moderators of Accuracy}

People's accuracy in estimating their partner's climate beliefs/behavior likely depends on a combination of three types of factors. We examine a (non-exhaustive) set of theoretically derived and practical exemplars of interpersonal factors (e.g., discussion), personal factors (e.g., attachment security), and relationship factors (e.g., relationship length, cohabitation). Below, we describe how each factor is expected to moderate the level of accuracy in partners' perceptions of each other's climate beliefs/behavior, with the goal of answering:

RQ4: Do relevant interpersonal, personal, or relationship factors determine who is more/less accurate in their understanding of their partner's beliefs/behavior?

Interpersonal discussion. People develop their own beliefs/behavior through learning the beliefs/behavior of others around them (i.e., the social norm; Bergquist et al., 2019; Cialdini et al., 1990; Jachimowicz et al., 2018). For example, people often update their beliefs to match the views of people they talk to (Druckman et al., 2018). But if people receive little or no direct information about the beliefs/behaviors of others, they might be more likely to misjudge them. This is a problem for generating action on climate change, especially when people inaccurately believe that others are not concerned about the issue (Abeles et al., 2019; Ballew et al., 2020; Mildenberger \& Tingley, 2019). When people (inaccurately) think that others are not concerned about climate change, people are hesitant to talk about the issue (Geiger \& Swim, 2016). However, when this misperception of the norm is corrected (i.e., most people are concerned about climate change), people become more willing to discuss it (Geiger \& Swim, 2016).

Although studies have examined norm perception accuracy across a wide range of domains (Fletcher \& Kerr, 2010; Miller \& Prentice, 2016), romantic partners' accuracy in estimating each other's climate change beliefs/behavior is unknown. One factor that is likely to influence accuracy is interpersonal discussion, which is an important way people learn from others and form their own beliefs (Amsalem \& Nir, 2019; Druckman et al., 2018; Goldberg et al., 2019). For example, respondents who were randomly assigned to discuss an environmental issue with a group of people were strongly persuaded in the direction of the views held by the discussion group members (Druckman et al., 2018). In the context of the current study, if romantic partners have never talked about climate change, they will lack explicit information about what their partner believes and does about climate change. If people are influenced by interpersonal discussions, then discussion should be a route by which people learn what their partner thinks. Thus, we hypothesize:

H2: People will be more accurate in their perceptions of their partner's climate beliefs/behavior when they discuss the issue, compared to when they do not.

Attachment security. An important personal factor that might help explain who is more or less accurate in estimating the beliefs/behavior of their partner is attachment security. Attachment security has two dimensions: avoidance and anxiety (Shaver \& Mikulincer, 2002). People low on both dimensions are considered securely attached — they are comfortable being close with their partner and are confident in being worthy of their partner's love. People with high avoidance are 
uncomfortable with closeness and have a strong desire for self-reliance. People with high anxiety desire closeness but have strong fears that their partner will abandon them, and often feel strong needs for reassurance from their partner (Fraley, 2019).

Attachment processes involve actively monitoring the environment for threats to security and for the availability of attachment figures. The sensitivity of the monitoring system is heightened for individuals who are higher in attachment anxiety, which has been referred to as hypervigilance (Shaver \& Mikulincer, 2002). Hypervigilance among the anxiously attached has been demonstrated for recognition of attachment figures' names (Mikulincer, Gillath, \& Shaver, 2002) and the onset and offset of emotional displays (Fraley, Niedenthal, Marks, Brumbaugh, \& Vicary, 2006). Moreover, attachment anxiety has been associated with greater accuracy for detecting deceit in non-romantic contexts (Ein-Dor \& Perr, 2014), and with more accurate memories of relationship quality (Chang \& Overall, 2022), and greater empathic accuracy during a relationally threatening discussion (Simpson, Kim, Fillo, Ickes, Rholes, Oriña, \& Winterheld, 2011) in a romantic context. This accuracy may plausibly extend to increased attention to a romantic partner's thoughts, feelings, and behavior more generally, and thus an increased accuracy in one's understanding of a partner's climate beliefs/behavior.

People higher in attachment avoidance, however, desire independence and self-reliance, and dismiss needs for intimacy and support (Shaver \& Mikulincer, 2002). They engage in a deactivating strategy in which they attempt to reduce monitoring for the availability of attachment figures (Shaver \& Mikulincer, 2007). Avoidantly attached people are less likely to engage in selfdisclosure or reciprocate the disclosure of others (Mikulincer \& Nachson, 1991). This constellation of distancing strategies suggests that people higher in attachment avoidance might be less accurate in their understanding of their partner's climate beliefs/behavior. We explore this idea in the current study.

Other potential moderators. We explored additional relationship factors that might moderate people's ability to accurately estimate their partner's climate beliefs and behavior: perceived partner responsiveness, relationship satisfaction, cohabitation, and relationship length.

Perceived partner responsiveness represents the extent to which one perceives their partner as attentive to and supportive of core aspects of one's self-concept (Reis et al., 2018; Crasta et al., 2021). Partners who are more responsive to one another may be more accurate in estimating each other's climate beliefs/behavior because a core feature of responsiveness is having one's opinions understood and valued.

Relationship satisfaction refers to the extent to which one is happy with their relationship (Funk \& Rogge, 2007). Partners who are satisfied with their relationship might be satisfied because of their understanding of, and agreement with one another. This suggests that relationship satisfaction may be associated with enhanced accuracy for their partners' beliefs/behavior in general, as well as their climate change beliefs/behavior more specifically.

Likewise, it is plausible to expect that cohabitation (living together with one's romantic partner) and relationship length (the duration of the couple's romantic relationship) would predict accuracy. Both factors reflect a greater number of opportunities for partners to learn about one another's beliefs/behavior, both day-to-day and over longer stretches of time. Because the topic of climate change is often seen as a controversial conversation topic (Geiger \& Swim, 2016), it's reasonable to expect that couples' understanding of one another's climate-related beliefs and behavior increases as their relationship progresses. The answers to these questions are yet unknown and thus we investigate them in the current study.

\section{The Current Study}


In the Introduction, we raised four primary research questions:

RQ1: How similar are the climate change beliefs and behaviors of romantic partners (i.e., correspondence)?

RQ2: How accurate and biased are people at estimating what their partner believes and how they behave with regard to climate change?

RQ3: Are people's perceptions of their partner's climate beliefs and behavior more strongly predicted by their partner's actual beliefs and behaviors (i.e., accuracy) or by projections of their own beliefs and behaviors (i.e., biased via assumed similarity)?

RQ4: Do relevant interpersonal, personal, or relationship factors determine who is more/less accurate in their understanding of their partner's beliefs/behavior?

These research questions are captured in a conceptual model shown in Figure 1.

Figure 1. Conceptual model of the relationship between each partner's beliefs/behaviors and their relationship with perceptions of one another

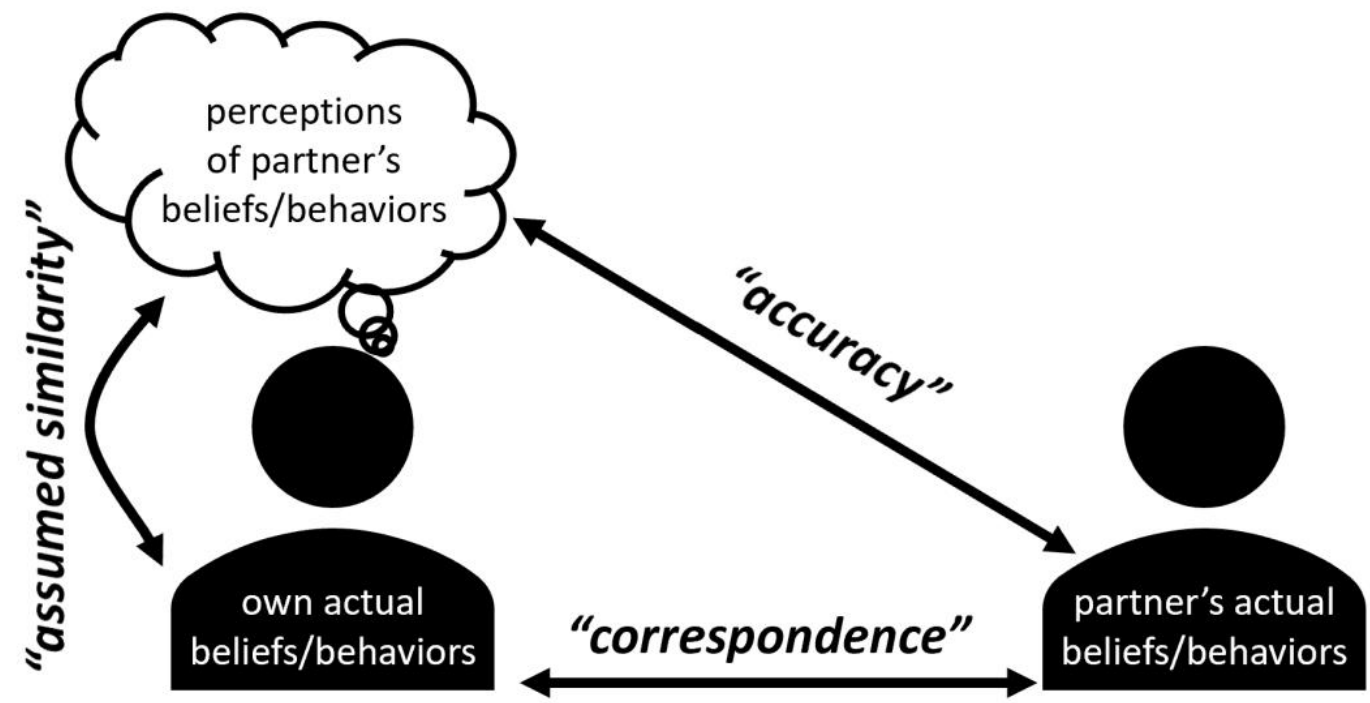

Note. Assumed similarity denotes the idea that people form perceptions of what their partner believes and how they behave based on their own beliefs/behavior. Correspondence refers to actual belief/behavior similarity within the couple. Accuracy refers to the extent to which people's perceptions of their partner's beliefs/behavior match their partner's actual beliefs/behavior.

To address the research questions, we surveyed 758 adult romantic couples (total $\mathrm{N}=$ 1,516) and asked them a variety of questions about their beliefs and behaviors regarding climate change (e.g., is climate change human-caused, are you worried about it, do you donate to organizations working on the issue?). Then we asked them to estimate their partner's climate beliefs/behaviors on the same questions. Finally, we asked respondents a wide range of questions about their relationship with their partner (e.g., relationship length, relationship satisfaction). Collecting data from both partners on these questions uniquely enables estimates of belief/behavior correspondence, accuracy of partner perceptions, moderators of accuracy, and the extent to which reality and assumed similarity account for people's perceptions of their partner's 
climate change beliefs/behavior. By investigating belief and behavior correspondence, how much perceptions of one's partner are rooted in truth or are a biased by one's own beliefs, and what predicts whether people are more or less accurate in their perceptions of their partner, this study helps us understand the degree to which romantic partners might be able to influence one another to be more pro-climate.

\section{Method}

\section{Data and Sample}

Data, survey materials, preregistration, and analysis code are available on our Open Science Framework project page at https://osf.io/aup7n/. This study was exempt from review by the Yale University Institutional Review Board. All procedures were preregistered unless stated otherwise. Respondents were recruited on the Prolific online survey platform between January 27 and February 13, 2021. Recruitment was conducted in two stages: 1) the initial confirmation of Prolific identification (ID) numbers and respondents' willingness to participate, and 2) recruitment into the full study. First, we used Prolific's built-in screener to select for respondents that reported (in the past 90 days) both they and their romantic partner would complete surveys on Prolific. Then we launched a short survey that asked respondents whether it was still true that they and their partner could participate and could do so independently. In this survey, we also asked respondents for their own Prolific ID number as well as that of their partner. This allowed us to check whether respondents provided a valid ID number for themselves and their partner, select only couples for which there was a valid ID for both partners, and select only respondents who said they and their partner could complete surveys independently. The resulting list of valid IDs was used to invite people to complete the full survey.

Because of uncertainties regarding response rates (i.e., both members of the couple complete the survey), we first tested the procedure on an initial sample and then used it as a rough estimate to scale up to the goal sample size, aiming for 800-1,000 couples. In total, 4,491 respondents were invited to participate in the full study, and 3,058 did so. All of the following exclusions were preregistered. Of the respondents who completed the full survey, 99\% $(n=3,019)$ reported that they and their partner could participate and do so independently. Of those respondents, $92 \%$ ( $\mathrm{n}=$ 2,768 ) provided valid IDs for themselves and their partner. Of the remaining respondents, $97 \%$ (n $=2,692$ ) passed the attention check. Respondents who failed to fulfill any of these criteria were excluded from analyses. Next, respondents' data were linked with their partners' data, if available. Consistent with our preregistered analysis plan, respondents who were identified as outliers for falling $-/+3$ standard deviations from the mean on the key global warming beliefs and behavior indices $(n=42)$ were removed from analyses. We also ran all analyses with these respondents included and results were substantively the same. These results are available for download on our OSF project page at https://osf.io/aup7n/. Because the research questions in the current study require data from both members of the couple, respondents were removed from the dataset if we could not also collect valid data from their partner, or if the couple's data could not be matched up (e.g., one partner typed in the incorrect identification number). Thus, all analyses in this article focus on the 758 couples (total $\mathrm{N}=1,516$ ) in which data from both partners were available, and both members passed all of the above checks.

Sample characteristics are displayed in Table 1. When recruiting respondents through Prolific, in an effort to recruit the desired number of couples, we did not place any restrictions on geographic location. Respondents from 29 countries participated. Most respondents (53\%) were from the United Kingdom $(n=471)$, United States $(n=221)$, or Portugal $(n=117)$. Country of 
residence was unknown for $14 \%(\mathrm{n}=214)$ of respondents. Exploratory analyses that examine variability based on country of residence can be found in the Supplementary Information.

Table 1. Sample characteristics

\begin{tabular}{lc}
\hline \multicolumn{1}{c}{ Variable } & Sample Characteristics \\
\hline$N$ & $1,516(758$ couples $)$ \\
\hline Age & $\mathrm{M}=30, \mathrm{SD}=8$ \\
\hline Sex & \\
Male & $49 \%$ \\
Female & $50 \%$ \\
Not listed & $1 \%$ \\
\hline Education & \\
No High School & $1 \%$ \\
High School & $14 \%$ \\
Some College & $18 \%$ \\
College Degree & $39 \%$ \\
Graduate Degree & $28 \%$ \\
\hline Race/Ethnicity & \\
White, non-Hispanic & $75 \%$ \\
Black, non-Hispanic & $3 \%$ \\
Other, non-Hispanic & $2 \%$ \\
Asian, non-Hispanic & $6 \%$ \\
Hispanic & $13 \%$ \\
Multiracial & $1 \%$ \\
\hline
\end{tabular}

\section{Measures}

Belief and behavior indices. Belief and behavior indices were constructed to reduce measurement error, as individual items are more vulnerable to error than the corresponding multiitem index. Further, indices were intended to capture a range of corresponding beliefs and behavior - with each item contributing substantively unique information related to a shared underlying construct. Four indices were calculated, each using the same items: one's own beliefs, one's own behaviors, perceptions of one's partner's beliefs, and perceptions of one's partner's behaviors.

Indices were scaled to be a standardized, regression-based factor score that was generated using maximum likelihood estimation. All items had strong loadings on a single factor. See Supplementary Tables 1-4 for detailed factor analysis results.

Global warming beliefs index. The index was adapted from Goldberg et al. (2021). The four items include people's beliefs about whether global warming is happening, whether it is humancaused, worry about it, and personal importance of the issue $(\alpha$ own $=0.79 ; \alpha$ Perceived Partner $=0.80)$. 
To measure personal importance, for example, we asked "how important is the issue of global warming to you personally?" (1 = Not at all important, 5 = Extremely important).

Global warming behavior index. Items were adapted from the Climate Change in the American Mind project (Leiserowitz et al., 2021). The behavior index included questions about how often one signs petitions supporting action on global warming, donates to organizations that are working to reduce global warming, posts on social media about global warming, and discusses the importance of global warming with friends and family ( $\alpha$ own $=0.78 ; \alpha$ Perceived Partner $=0.77)$. The four questions were part of a single block that began with "Over the past 12 months, how often, if ever, have you done the following?" with each of the behaviors listed (e.g., donated money to an organization working to reduce global warming) and response options ranging from (1) Never to (4) Often.

The behaviors included in this index were chosen, in part, to ensure that they varied in their level of observability (i.e., how easily one partner might observe the other partner's behavior). Although there was no precise way to define the extent to which these behaviors differed in observability, we proceeded based on the idea that a behavior is more observable if other people can identify you as you perform the behavior (Kraus \& Callaghan, 2016). Thus, posting on social media and discussing global warming with friends and family are observable by definition whereas signing a petition or donating do not necessitate observation by others.

\section{Interpersonal measure.}

Global warming discussion. The measure of global warming discussion was adapted from previous research (Goldberg et al., 2019). The question was: "How often do you discuss global warming with your partner?" with response options ranging from (1) Never to (4) Often.

\section{Personal measures.}

Attachment security. Attachment security was measured with nine items that comprise two factors: attachment avoidance (six items; $\square=.82$ ) and attachment anxiety (three items; $\alpha=.83$; Fraley, Heffernan, Vicary, \& Brumbaugh, 2011). Response options range from Strongly disagree (1) to Strongly agree (7). For example, avoidance was measured with items such as “I don't feel comfortable opening up to my partner" and anxiety was measured with items such as "I'm afraid my partner may abandon me."

\section{Relationship measures}

Perceived partner responsiveness. Perceived partner responsiveness was measured with a matrix of three items $(\alpha=.83)$ starting with the stem "My partner usually..." and the statements "values my abilities and opinions," "understands me," and "makes me feel cared for" ( $1=$ Not at all true, 7 = Completely true; Reis, Crasta, Rogge, Maniaci, \& Carmichael, 2018)

Relationship satisfaction. Relationship satisfaction was measured with one item (Funk \& Rogge, 2007). Respondents were oriented to the question with the prompt: "The choices on the following scale represent different degrees of happiness in your relationship. The middle point, "Happy" represents the degree of happiness of most relationships. Please select the answer which best describes the degree of happiness, all things considered, of your relationship." Respondents were asked to choose from a set of options ranging from Extremely unhappy (1) to Perfect (7).

Other measures. We also measured whether the couple lived together (and, if so, for how long), how long they have been in a relationship, and whether or not they are married. See the OSF project page for the full survey instrument. 


\section{Procedure}

Upon entering the main survey, respondents were thanked for their time. We then asked for their Prolific ID number and their partner's ID number, and confirmed that they and their partner could complete the survey independently. Then respondents answered questions about their own global warming beliefs and behaviors. Once this block was complete, respondents were given detailed instructions describing that we were interested in asking about their perceptions of what their partner believes and how they behave. We emphasized that they should not ask their partner for this information and we assured them that their answers would not be shared with their partner. Respondents were asked to confirm that they understood the instructions. After confirming, respondents completed all the same global warming beliefs and behaviors questions regarding how they think their partner would answer. Then respondents were given an attention check question (see the survey on the OSF project page). After this question, respondents completed a series of questions about their romantic relationship (length, satisfaction, attachment security, etc.). Finally, respondents answered demographic questions.

\section{Analytic Approach}

Consistent with our preregistration, we used multilevel models for all key estimates and hypothesis tests. We compared the relative size of estimates using Z-tests (Paternoster, Brame, Mazerolle, \& Piquero, 1998). To conduct the appropriate analyses testing the research questions of interest, it is necessary to restructure the data into "pairwise" format (Kenny et al., 2006, p. 18). This data structure includes, for each row, one's own responses as well as those of their partner, and vice versa (see Ledermann \& Kenny, 2014).

Belief and behavior correspondence. Intraclass correlations were used to estimate belief correspondence within couples, which we interpret as "the proportion of variation in the outcome measure that is accounted for by the dyad" (Kenny et al., 2006, pp. 33-34). Standard errors and confidence intervals for intraclass correlations were computed using a parametric bootstrapping procedure.

Perceived versus actual partner beliefs and behavior. We use the Actor-Partner Interdependence Model (APIM) for indistinguishable dyads to test the extent to which people's own beliefs/behavior (bias) and their partner's beliefs/behavior (accuracy) predict what they think their partner believes and how they behave. For the underlying logic and technical details behind this model, see Kenny et al. (2006, pp. 144-184). Put simply, these models estimate accuracy (i.e., whether perceptions of one's partner reflect reality) and assumed similarity (i.e., how much people's own beliefs/behavior predict perceptions of their partner). More specifically, respondents were nested in couples, predictors were one's own beliefs [behavior] and their partner's beliefs [behavior], and the dependent variable was perception of one's partner's beliefs [behavior]. It is important to examine the predictive strength of both predictor variables (i.e., own beliefs/behavior and partner's beliefs/behavior) in the same model, because examining either one alone would likely result in overestimating its importance (Kenny \& Cook, 1999). In other words, the models estimate the unique contributions of one's own beliefs/behavior (i.e., assumed similarity) and those of their partner (i.e., accuracy). Interaction effects were tested within the APIM framework, with an interaction term (and corresponding main effects) between one's partner's beliefs/behavior and the moderator of interest.

\section{Results}

\section{RQ1: Correspondence}


First, we examined RQ1, correspondence. We used random effects intercept-only models to estimate correspondence - the proportion of variation in global warming beliefs and behavior that is accounted for by the couple (i.e., intraclass correlation; ICC). We estimated global warming belief correspondence between romantic partners to be $38 \%$ (ICC $=.38,95 \%$ CI [.32, .44]). There was a similar degree of correspondence between romantic partners' global warming behaviors: $31 \%(\mathrm{ICC}=.31,95 \%$ CI $[.25, .37])$.

\section{RQ2: Accuracy and Bias}

Next, we answered RQ2, accuracy and bias, using APIMs (Kenny et al., 2006). Our preregistered hypotheses ${ }^{2}$ did not specify whether perceptions of a romantic partner's beliefs and behaviors would be more strongly predicted by one's own beliefs/behaviors or by the romantic partner's actual beliefs and behaviors. As specified by H1, however, we hypothesized that both variables would be positive predictors of perceptions. Results confirm H1 (Figure 2). These results represent a couple-oriented pattern in which perceptions are expected to be shaped both by reality (truth) and by assumptions that one's partner believes and behaves similarly to oneself (bias; Kenny et al., 2006; West \& Kenny, 2011).

\section{RQ3: Relative Strength of Accuracy and Bias}

Next, we examined RQ3, relative strength of accuracy and bias. As shown in Figure 2 (left panel), a partner's actual beliefs were a significantly stronger predictor of perceptions of the partner's beliefs than were one's own beliefs. Put simply, the accuracy effect was stronger than the assumed similarity effect for perceived partner beliefs. Looking at perceptions of partner's behavior (right panel), however, one's own behavior was a significantly stronger predictor of perceptions of the partner's behavior than was the partner's report of their own behavior. In other words, the assumed similarity effect was stronger than the accuracy effect for perceived partner behavior.

Figure 2. Models predicting perceptions of partner beliefs and behavior

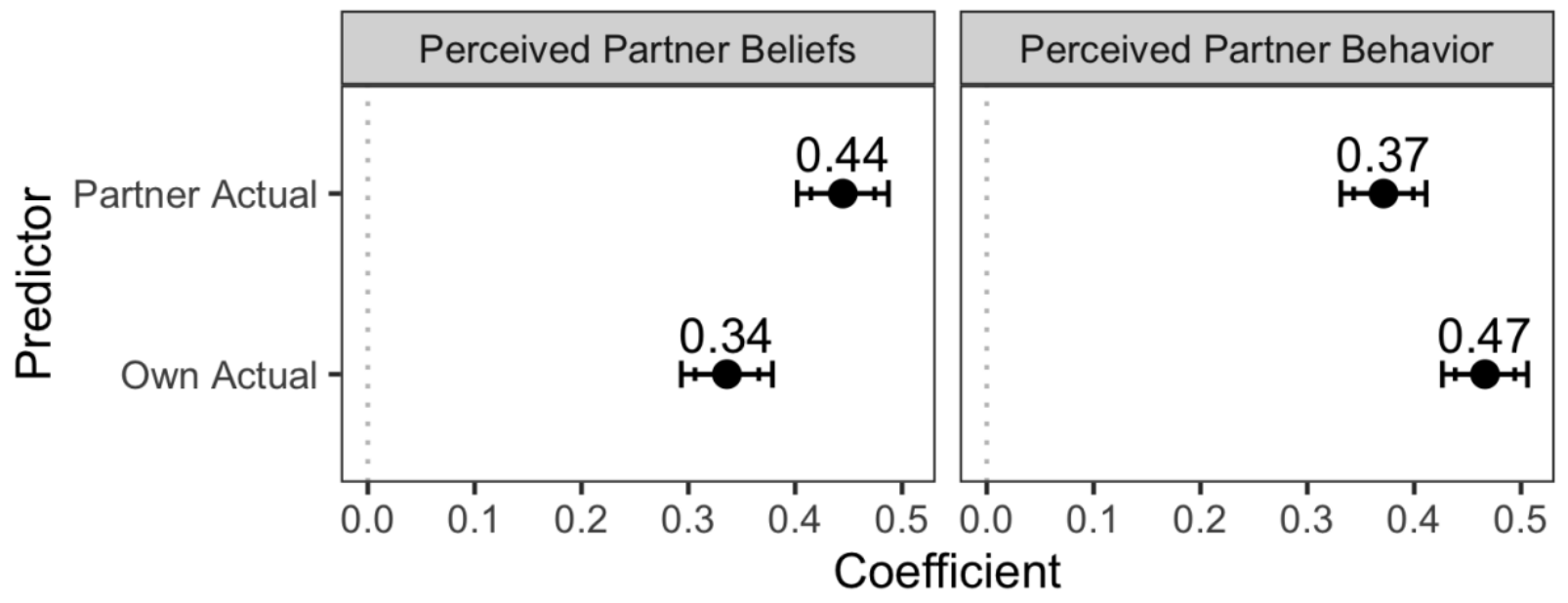

\footnotetext{
${ }^{2}$ Preregistered hypotheses are evaluated using one-tailed tests and therefore, where appropriate, $p$-values are adjusted to reflect this. All other relationships are evaluated using two-tailed tests. However, in order to convey the same confidence level for all tests, we report $95 \%$ confidence intervals throughout the manuscript. Additionally, in the interest of brevity and clarity of the manuscript, we present tests of additional hypotheses in the Supplementary Information.
} 
Note. Coefficients are standardized. The left panel displays one's own and partner's beliefs predicting perceptions of partner's beliefs. The right panel displays one's own and partner's behavior predicting perceptions of partner's behavior. Outside error bars represent bootstrap 95\% confidence intervals with 2,000 resamples. Inside error bars represent bootstrap $83 \%$ confidence intervals with 2,000 resamples, which are plotted to aid visual comparisons of significant differences between coefficients at the $\mathrm{p}=.05$ alpha level (Goldstein \& Healy, 1995).

\section{RQ4: Moderators of Accuracy}

Next, we investigated RQ4 (i.e., moderators of accuracy). As detailed in H2, we hypothesized that accuracy would be stronger among people who have discussed global warming with their partner, compared to those who have not. Consistent with this hypothesis, a significant interaction provides evidence that perceptions of partner's beliefs were more accurate for people who say they discuss global warming with their partner, compared to those who say they never do $(\beta=$ $0.18, p<.001), 95 \%$ CI $[0.08,0.28]$. There was a similar significant interaction for behavior $(\beta=$ $0.14, p=.009$ ), 95\% CI [0.03, 0.26] (Figure 3). In other words, people were more accurate in their perceptions of their partner's global warming beliefs and behavior if they discussed global warming with their partner.

Figure 3. Interactions between partner's beliefs/behavior and global warming discussion
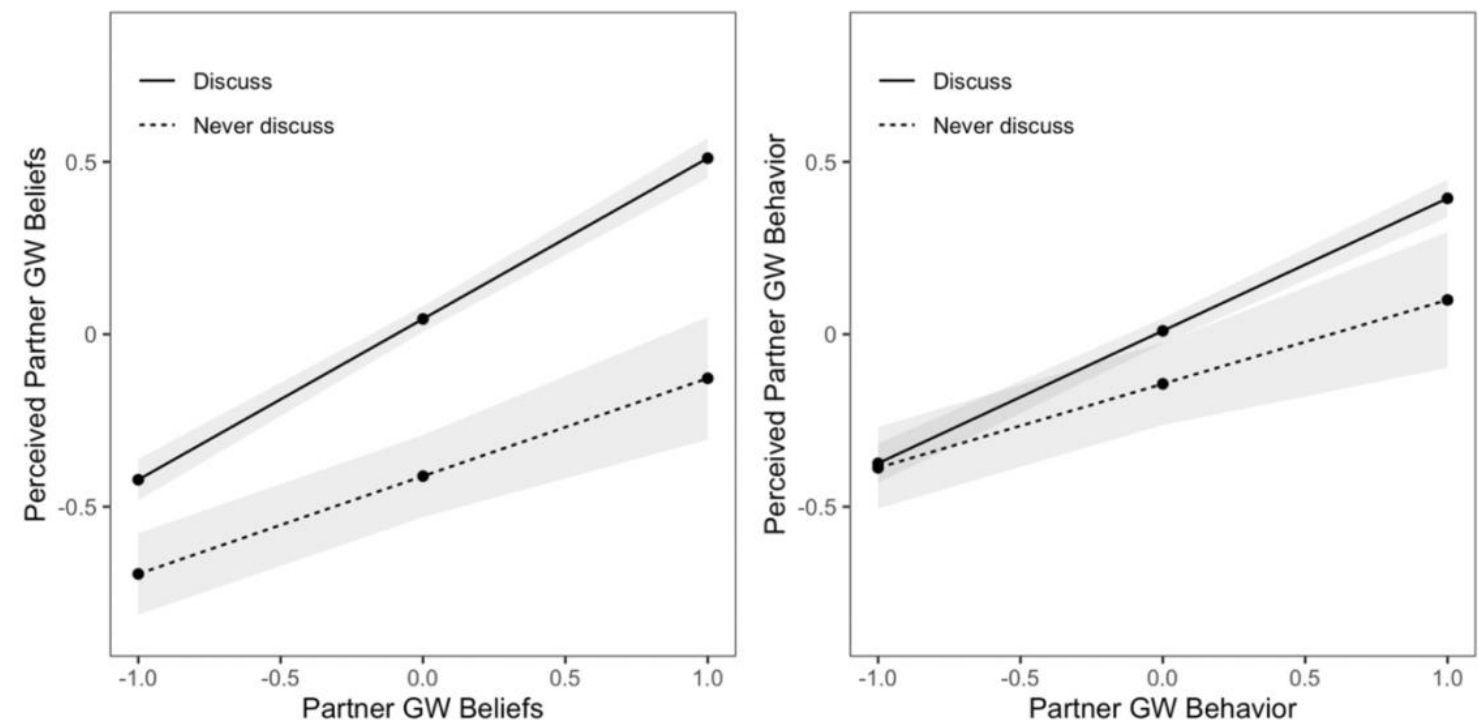

Note. People are more accurate in their perceptions of their partner's beliefs (left panel) and behavior (right panel) if they discuss global warming with their partner. Shaded area around the fit line represents the $95 \%$ confidence interval. Dots represent predicted values of the corresponding dependent measure when partner GW beliefs/behavior is at -1 standard deviation, the mean, and +1 standard deviation, while also controlling for respondents' own beliefs/behavior in the corresponding model. $\mathrm{GW}=$ Global warming.

Further investigating RQ4, we examined six additional relationship-specific variables as moderators of the relationship between perceived and actual partner beliefs/behavior. These additional moderators included attachment security (anxiety and avoidance), perceived partner responsiveness, relationship satisfaction, cohabitation, and relationship length. Consistent with our other analyses, the belief and behavior dependent measures are considered tests of different phenomena, and hence two separate families of hypothesis tests. To guard against the increased risk of false positives, we applied a Bonferroni correction by dividing the original alpha level by 
six $(.05 / 6=.008)$. We only explored interactions further if they met or surpassed this stricter threshold. See Supplementary Tables 5-16 for full results on all models we tested.

The only interaction that was significant at the .008 level was for attachment anxiety, with the global warming behavior index as the dependent measure $(\beta=0.06, p=.005), 95 \% \mathrm{CI}[0.02$, $0.10]$. The relationship between a partner's behavior and one's perceptions of it was positive and strong for all levels of attachment anxiety, but this relationship was significantly stronger at higher levels of anxiety. In other words, anxiously attached respondents - people who are relatively hypervigilant to their romantic partner's cues - were more accurate in their perceptions of their partner's global warming-related behavior. We did not observe the same pattern for the beliefs dependent measure, $(\beta=-0.02, p=.343), 95 \%$ CI [-0.06, 0.02] (Supplementary Table 7). Segmentation Analyses

To further develop a practical understanding of the results, we used the Global Warming's Six Americas ${ }^{3}$ framework to categorize people and their partners into six distinct segments of the population based on their climate beliefs, attitudes, and behaviors (Leiserowitz et al., 2021; Maibach et al., 2011). Segments range from the "Alarmed"- - who are very worried about global warming and are highly engaged in the issue - to the "Dismissive" who reject the idea that global warming is happening and are hostile to the idea of taking pro-climate action. Calculating Six Americas segments for people and their partners allows for a practical overview of how frequently we observe cases in which one partner is Alarmed and the other partner is in a less-engaged segment (e.g., "Concerned" or "Cautious"). As shown in Figure 4, although it is common for partners to be in the same segment (47\%), it is also common for couples to include one partner who is Alarmed and one who is Concerned or Cautious (35\%). It was extremely uncommon for partners to be on opposite sides of the spectrum. Taken together, the prevalence of partners placing in different segments suggests that there is ample opportunity for people to influence their partners to believe and act in more pro-climate ways.

Figure 4. Correspondence between one's own Six Americas segment and that of one's partner

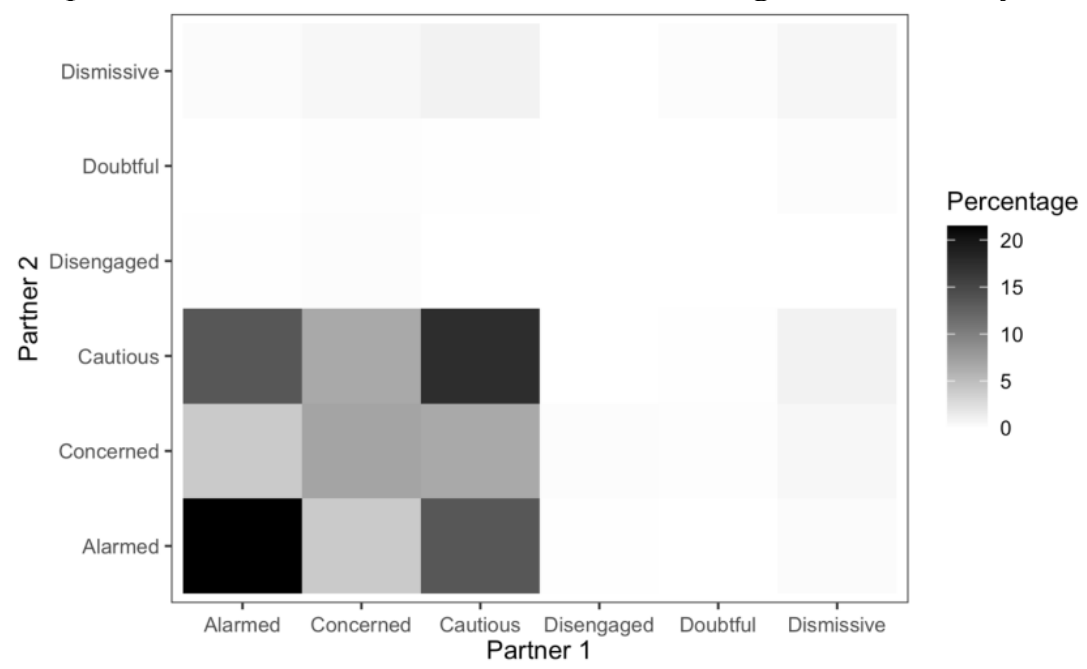

\footnotetext{
${ }^{3}$ It is worth noting that, although this framework was originally developed for use in the United States, it has since been used across many countries and territories around the world (Leiserowitz et al., 2021). Further, the results from segmentation analyses are highly dependent on the variables used as inputs for the segmentation. Thus, choices about how to segment a given population should depend on the intended use of the results (Füchslin, 2019).
} 
Note. Figure shows the correspondence between romantic partners on their Six Americas segment. Shading is scaled to the percentage of the sample. Values below and above the diagonal are identical because of the dyadic data structure.

\section{Discussion}

The current study provides several novel findings about romantic couples and their climate change beliefs and behaviors. First, romantic partners exhibit similar climate change beliefs and behaviors. However, our measures of correspondence and our segmentation analysis also revealed a pattern of discrepancies between many partners in their beliefs and attitudes about climate change, suggesting opportunities for one partner to influence the other. Given the degree to which romantic partners influence one another (Christakis \& Fowler, 2008; Rossignac-Milon et al., 2020; Smith \& Mackie, 2016), these relationships offer a unique opportunity to develop intimate social norms that could foster shifts toward pro-climate beliefs and behavior (similar to the way one's social circle might influence one's decision to get a flu vaccine, smoke, or exercise; Berli et al., 2018; Christakis \& Fowler, 2008; de Bruin et al., 2019; Lewis \& Butterfield, 2007). One possibility is that people who are with a pro-environment romantic partner become more proenvironment themselves through self-expansion processes (Aron et al., 1991). However, it is important to note that this might not happen without a coordinated intervention. For example, across a wide range of issues including climate change, romantic partners often change in their beliefs independently of one another (Hammond \& Sibley, 2022). This does not necessarily mean social influence has failed. Rather, it highlights the possibility that social influence may not have been attempted.

The above considerations highlight the need for additional research to understand when and how influence might occur. One useful place to start is to adapt the Dyadic Health Influence Model (Huelsnitz et al., 2022) to the context of climate change beliefs/behavior. Doing so may provide theoretical and practical value to understanding how partners influence one another directly and indirectly, such as through direct attempts to influence, by modeling one's own behavior (e.g., attending protests), or by other means.

Confirming H1, we found that partners' perceptions of each other's climate beliefs and behaviors were both accurate and biased: a substantial amount of the variability in perceptions is accounted for by a person's own beliefs/behavior (assumed similarity) and also by their partner's actual beliefs/behavior (accuracy). These findings extend the literature on accuracy and bias in romantic perception (Fletcher, 2015) by testing the Truth and Bias Model (Stern \& West, 2018; West \& Kenny, 2011) in a new domain and finding perceived climate change beliefs and behaviors are likely shaped by both reality and assumed similarity (Kenny \& Acitelli, 2001).

In an effort to better understand how romantic partners might learn about each other's climate beliefs and behaviors, we examined whether perceptions of partner's beliefs and behaviors were more accurate among couples who discuss global warming compared to those who do not. Confirming H2, we found that partners who discuss global warming with one another had more accurate perceptions of each other's actual beliefs and behavior, compared to partners who do not discuss global warming. This is consistent with research and theory on social norms: people learn about the beliefs, behaviors, and expectations of others (i.e., norms) when their attention is drawn to those norms (e.g., Bergquist et al., 2019; Cialdini et al., 1990). Although we cannot make causal claims from our data, it may be that cultivating conversations about global warming between partners can trigger conformity to social norms by making their partner's views more apparent. The propensity toward identity fusion (Agnew et al., 1998; Aron et al., 1991; Walsh \& Neff, 2018) may bring couples' global warming beliefs and behavior into greater alignment the more they discuss these issues. 
However, it is also possible that when partners with discrepant beliefs discuss global warming, the less-concerned partner may persuade the more-concerned partner to move in their direction. A practical contribution of this study is the finding that it is more common for a couple to include a partner who is Alarmed about climate change and a partner who is less engaged in the issue (and thus, is more likely to be influenced) than a couple where one partner is Dismissive and the other partner is less engaged. Still, interventions could be designed to provide the more concerned partner with informational resources and conversational strategies to help them have a positive impact on their partner's beliefs and behaviors. It would be fruitful for future research to identify factors that predict which couples are most productive to engage with (e.g., with microtargeting models; Metcalf et al., 2019). Our study suggests that one place to start is to find couples in which at least one partner is Alarmed, but little or no discussion about the issue has occurred yet between the partners.

We also found that people who were higher in attachment anxiety (i.e., fearful of abandonment, and doubtful of their partner's love) had perceptions of their partner's global warming behavior that more closely matched their partner's actual behavior, compared to those who were relatively lower in anxiety. Attachment anxiety has been described as a hyperactivating strategy (Shaver \& Mikulincer, 2002), which involves excessive distress and hypervigilance to a partner's behavior in response to signs of threat. In addition to more accurately detecting deceit (Ein-Dor \& Perry, 2014) and emotion (Simpson et al., 2011), and better remembering relationship quality (Chang \& Overall, 2022), people who are higher in attachment anxiety appear to be more accurate, overall, in their perceptions of their partner's climate behavior, perhaps because they are often paying closer attention. It is unclear, however, why accuracy was not also moderated by attachment avoidance.

Further, accuracy was not moderated by perceived partner responsiveness, relationship satisfaction, cohabitation, or relationship length. Although the specific reasons for each moderator is likely to vary, one general explanation is that people learn their partner's climate beliefs/behavior early in the relationship. If this is the case, factors such as cohabitation or relationship length would add little additional accuracy because people have already learned most of the relevant information about their partner.

Findings from this study should be considered in light of its limitations. First, there was no experimental manipulation and therefore we cannot make causal claims. However, the current results suggest that it would be valuable for applied experimental research to test the effectiveness of engaging romantic partners as climate change messengers.

Further, ambiguity about the causal relationships between our measured variables leaves unclear the process by which couples develop their climate beliefs and behaviors. For example, people might infer their partner's beliefs through observing their behaviors, via discussion, or through some other route. Experimental research is needed to disentangle the different potential causal relationships.

Additionally, because behavior was self-reported, it is unknown how closely our results would correspond with more objective measures of behavior. It is plausible that larger (or smaller) differences between beliefs and behavior might be observed depending on how behaviors are measured. Further, results might depend on which behaviors are measured. Looking more closely at the results using the individual items that form the behavior index, for example, we observe that accuracy was highest for the behavior that is presumably the most observable: posting about global warming on social media (see Supplementary Tables 17-24). Perhaps, for the other behaviors measured, people relied more heavily on their own behaviors as a heuristic, which might have reduced accuracy. However, in the context of romantic relationships, it is difficult to 
neatly differentiate between behaviors that are observable and those that are not (e.g., certain behaviors might be more observable than others, but this might depend on whether partners live together). It would be valuable for future research to address these limitations.

And finally, it is important to think critically about the generalizability of these findings (Simons et al., 2017). The fact that the sample included respondents from many different countries leaves unclear whether these findings represent a larger target population (e.g., couples across the world). However, our analyses split by country of residence provides empirical evidence for the claim that our specific estimates might vary in magnitude, but are unlikely to affect our general conclusions (e.g., people are both accurate and biased in their understanding of what their partner believes and how they behave regarding climate change). Further, applying the Six Americas segmentation to a mixed, international sample shows that, even if the specific segment sizes vary widely, the framework still provides helpful practical guidance for understanding populations outside of the United States. Either way, deeper questions about generalizability await empirical confirmation.

Another interesting question for future research is why a person's perceptions of their partner's beliefs/behavior were so strongly predicted by their own beliefs/behavior (assumed similarity). In addition, people's own behavior was a significantly stronger predictor of partner perceptions than the partner's actual behavior. Among the potential explanations for this assumed similarity effect, several suggest that people use their own beliefs/behaviors as a heuristic for estimating their partner's beliefs/behavior (Marks \& Miller, 1987). This has important practical implications because it can lead people to mistakenly believe that their partner is more (or less) engaged in climate issues than they actually are.

To conclude, researchers and climate advocates can use these findings to inform future studies that can help us better understand the dynamics of climate change beliefs and behaviors within romantic relationships. Taken together, the correspondence, accuracy, and bias revealed by our research suggests that romantic relationships may be fruitful domains for strategic interventions, and underscores the importance of discussing global warming with one's romantic partner.

\section{References}

Abeles, A. T., Howe, L. C., Krosnick, J. A., \& MacInnis, B. (2019). Perception of public opinion on global warming and the role of opinion deviance. Journal of Environmental Psychology, 63, 118-129. https://doi.org/10.1016/i.jenvp.2019.04.001

Agnew, C. R., Van Lange, P. A., Rusbult, C. E., \& Langston, C. A. (1998). Cognitive interdependence: Commitment and the mental representation of close relationships. Journal of Personality and Social Psychology, 74, 939-954. doi:10.1037/0022-3514.74.4.939.

Amsalem, E., \& Nir, L. (2019). Does Interpersonal Discussion Increase Political Knowledge? A Meta-Analysis. Communication Research, 009365021986635. https://doi.org/10.1177/0093650219866357

Aron, A., Aron, E. N., Tudor, M., \& Nelson, G. (1991). Close relationships as including other in the self. Journal of Personality and Social Psychology, 60(2), 241-253. https://doi.org/10.1037/ 0022-3514.60.2.241

Ballew, M. T., Rosenthal, S. A., Goldberg, M. H., Gustafson, A., Kotcher, J. E., Maibach, E. W., \& Leiserowitz, A. (2020). Beliefs about others' global warming beliefs: The role of party affiliation and opinion deviance. Journal of Environmental Psychology, 70, 101466. https://doi.org/10.1016/i.jenvp.2020.101466

Bar-Kalifa, E., Rafaeli, E., \& Sened, H. (2016). Truth and bias in daily judgments of support receipt between romantic partners. Personal Relationships, 23(1), 42-61.

Bergquist, M., Nilsson, A., \& Schultz, W. P. (2019). A meta-analysis of field-experiments using social norms to promote pro-environmental behaviors. Global Environmental Change, 59, 101941. https://doi.org/10.1016/j.gloenvcha.2019.101941

Berli, C., Bolger, N., Shrout, P. E., Stadler, G., \& Scholz, U. (2018). Interpersonal processes of couples' daily support for goal pursuit: The example of physical activity. Personality and Social Psychology Bulletin, 44(3), 332-344. https://doi.org/10.1177/0146167217739264 
Bruine de Bruin, W., Parker, A. M., Galesic, M., \& Vardavas, R. (2019). Reports of social circles' and own vaccination behavior: A national longitudinal survey. Health Psychology, 38(11), 975-983. https://doi.org/10.1037/hea0000771

Byrne, D. (1961). Interpersonal attraction and attitude similarity. The Journal of Abnormal and Social Psychology, 62, 713-715. http://dx.doi .org/10.1037/h0044721

Carmichael, C. L., Goldberg, M. H., \& Coyle, M. A. (2020). Security-Based Differences in Touch Behavior and Its Relational Benefits. Social Psychological and Personality Science, 1948550620929164. https://doi.org/10.1177/1948550620929164

Chang, V. T., \& Overall, N. C. (2022). Attachment anxiety, tracking accuracy, and biased memory of prior relationship evaluations. Personal Relationships.

Christakis, N. A., \& Fowler, J. H. (2008). The Collective Dynamics of Smoking in a Large Social Network. New England Journal of Medicine, 358(21), 2249-2258. https://doi.org/10.1056/NEJMsa0706154

Cialdini, R. B., Reno, R. R., \& Kallgren, C. A. (1990). A Focus Theory of Normative Conduct: Recycling the Concept of Norms to Reduce Littering in Public Places. Journal of Personality and Social Psychology, 58(6), 1015-1026.

Crasta, D., Rogge, R. D., Maniaci, M. R., \& Reis, H. T. (2021). Toward an optimized measure of perceived partner responsiveness: Development and validation of the perceived responsiveness and insensitivity scale. Psychological Assessment, 33(4), 338-355. https://doi.org/10.1037/pas0000986

Druckman, J. N., Levendusky, M. S., \& McLain, A. (2018). No Need to Watch: How the Effects of Partisan Media Can Spread via Interpersonal Discussions. American Journal of Political Science, 62(1), 99-112. https://doi.org/10.1111/ajps.12325

Ein-Dor, T., \& Perry, A. (2014). Full house of fears: Evidence that people high in attachment anxiety are more accurate in detecting deceit. Journal of Personality, 82(2), 83-92.

Fletcher, G. J. (2015). Accuracy and bias of judgments in romantic relationships. Current Directions in Psychological Science, 24(4), 292-297.

Fletcher, G. J., \& Kerr, P. S. (2010). Through the eyes of love: reality and illusion in intimate relationships. Psychological bulletin, 136(4), 627.

Fraley, R. C. (2019). Attachment in adulthood: Recent developments, emerging debates, and future directions. Annual review of psychology, 70, 401-422.

Fraley, R. C., Heffernan, M. E., Vicary, A. M., \& Brumbaugh, C. C. (2011). The Experiences in Close RelationshipsRelationship Structures questionnaire: A method for assessing attachment orientations across relationships. Psychological Assessment, 23, 615-625.

Fraley, R. C., Niedenthal, P. M., Marks, M., Brumbaugh, C., \& Vicary, A. (2006). Adult attachment and the perception of emotional expressions: Probing the hyperactivating strategies underlying anxious attachment. Journal of Personality, 74(4), 1163-1190.

Füchslin, T. (2019). Science communication scholars use more and more segmentation analyses: Can we take them to the next level? Public Understanding of Science, 28(7), 854-864. https://doi.org/10.1177/0963662519850086

Funk, J. L., \& Rogge, R. D. (2007). Testing the ruler with item response theory: Increasing precision of measurement for relationship satisfaction with the Couples Satisfaction Index. Journal of Family Psychology, 21(4), 572-583. https://doi.org/10.1037/0893-3200.21.4.572

Gagné, F. M., \& Lydon, J. E. (2004). Bias and accuracy in close relationships: An integrative review. Personality and Social Psychology Review, 8(4), 322-338.

Geiger, N., \& Swim, J. K. (2016). Climate of silence: Pluralistic ignorance as a barrier to climate change discussion. Journal of Environmental Psychology, 47, 79-90. https://doi.org/10.1016/i.jenvp.2016.05.002

Goldberg, M. H., Gustafson, A., Rosenthal, S. A., \& Leiserowitz, A. (2021). Shifting Republican views on climate change through targeted advertising. Nature Climate Change, 1-5. https://doi.org/10.1038/s41558-02101070-1

Goldberg, M. H., van der Linden, S., Maibach, E., \& Leiserowitz, A. (2019). Discussing global warming leads to greater acceptance of climate science. Proceedings of the National Academy of Sciences, 116(30), 1480414805. https://doi.org/10.1073/pnas.1906589116

Goldstein, H., \& Healy, M. J. R. (1995). The Graphical Presentation of a Collection of Means. Journal of the Royal Statistical Society, 158(1), 175-177. https://doi.org/10.2307/2983411

Hammond, M. D., \& Sibley, C. G. (2022). Romantic Partners Are Similar in Their Well-Being and Sociopolitical Attitudes but Change Independently Over Time. Social Psychological and Personality Science, 13(1), 199209. 
Huelsnitz, C. O., Jones, R. E., Simpson, J. A., Joyal-Desmarais, K., Standen, E. C., Auster-Gussman, L. A., \& Rothman, A. J. (2022). The Dyadic Health Influence Model. Personality and Social Psychology Review, 26(1), 3-34. https://doi.org/10.1177/10888683211054897

Jachimowicz, J. M., Hauser, O. P., O’Brien, J. D., Sherman, E., \& Galinsky, A. D. (2018). The critical role of second-order normative beliefs in predicting energy conservation. Nature Human Behaviour, 2(10), $757-$ 764. https://doi.org/10.1038/s41562-018-0434-0

Kenny, D. A., \& Acitelli, L. K. (2001). Accuracy and bias in the perception of the partner in a close relationship. Journal of Personality and Social Psychology, 80(3), 439-448.

Kenny, D. A., \& Cook, W. (1999). Partner effects in relationship research: Conceptual issues, analytic difficulties, and illustrations. Personal Relationships, 6(4), 433-448. https://doi.org/10.1111/j.14756811.1999.tb00202.x

Kenny, D. A., Kashy, D. A., \& Cook, W. L. (2006). Dyadic data analysis. Guilford Press.

Ledermann, T., \& Kenny, D. A. (2015). A toolbox with programs to restructure and describe dyadic data. Journal of Social and Personal Relationships, 32(8), 997-1011. https://doi.org/10.1177/0265407514555273

Leiserowitz, A. (2019). Building public and political will for climate action. In Esty, D. (ed.) A Better Planet: 40 Big Ideas for a Sustainable Future. Yale University Press.

Leiserowitz, A., Carman, J., Buttermore, N., Wang, X., Rosenthal, S., Marlon, J., \& Mulcahy, K. (2021). International Public Opinion on Climate Change. New Haven, CT: Yale Program on Climate Change Communication and Facebook Data for Good.

Leiserowitz, A., Maibach, E., Rosenthal, S., Kotcher, J., Carman, J., Neyens, L., Marlon, J., Lacroix, K., \& Goldberg, M. (2021). Climate change in the American Mind: September 2021. Yale University and George Mason University. New Haven, CT: Yale Program on Climate Change Communication.

Leiserowitz, A., Roser-Renouf, C., Marlon, J., \& Maibach, E. (2021). Global Warming's Six Americas: A review and recommendations for climate change communication. Current Opinion in Behavioral Sciences, 42, 97-103. https://doi.org/10.1016/j.cobeha.2021.04.007

Lewis, M. A., \& Butterfield, R. M. (2007). Social control in marital relationships: Effect of one's partner on health behaviors1. Journal of Applied Social Psychology, 37(2), 298-319. https:// doi.org/10.1111/j.00219029.2007.00161.x

Maibach, E. W., Leiserowitz, A., Roser-Renouf, C., \& Mertz, C. K. (2011). Identifying Like-Minded Audiences for Global Warming Public Engagement Campaigns: An Audience Segmentation Analysis and Tool Development. PLoS ONE, 6(3), e17571. https://doi.org/10.1371/journal.pone.0017571

Marks, G., \& Miller, N. (1987). Ten Years of Research on the False-Consensus Effect: An Empirical and Theoretical Review. Psychological Bulletin, 102(1), 72-90.

Metcalf, A. L., Angle, J. W., Phelan, C. N., Muth, B. A., \& Finley, J. C. (2019). More "Bank" for the Buck: Microtargeting and Normative Appeals to Increase Social Marketing Efficiency. Social Marketing Quarterly, 25(1), 26-39. https://doi.org/10.1177/1524500418818063

Mikulincer, M., Gillath, O., \& Shaver, P. R. (2002). Activation of the attachment system in adulthood: Threat-related primes increase the accessibility of mental representations of attachment figures. Journal of Personality and Social Psychology, 83, 881-895.

Mikulincer, M., \& Nachshon, O. (1991). Attachment styles and patterns of self-disclosure. Journal of Personality and Social Psychology, 61(2), 321.

Mildenberger, M., \& Tingley, D. (2019). Beliefs about Climate Beliefs: The Importance of Second-Order Opinions for Climate Politics. British Journal of Political Science, 49(4), 1279-1307. https://doi.org/10.1017/S0007123417000321

Miller, D. T., \& Prentice, D. A. (2016). Changing Norms to Change Behavior. Annual Review of Psychology, 67(1), 339-361. https://doi.org/10.1146/annurev-psych-010814-015013

Ockwell, D., Whitmarsh, L., \& O’Neill, S. (2009). Reorienting Climate Change Communication for Effective Mitigation: Forcing People to be Green or Fostering Grass-Roots Engagement? Science Communication, 30(3), 305-327. https://doi.org/10.1177/1075547008328969

Paternoster, R., Brame, R., Mazerolle, P., \& Piquero, A. (1998). Using the correct statistical test for the equality of regression coefficients. Criminology, 36(4), 859-866. https://doi.org/10.1111/j.1745-9125.1998.tb01268.x

Reis, H. T., Clark, M. S., \& Holmes, J. G. (2004). Perceived Partner Responsiveness as an Organizing Construct in the Study of Intimacy and Closeness. In D. J. Mashek \& A. P. Aron (Eds.), Handbook of closeness and intimacy (pp. 201-225). Lawrence Erlbaum Associates Publishers.

Reis, H.T., Crasta, D., Rogge, R.D., Maniaci, M.R., \& Carmichael, C.L. (2018). Perceived partner responsiveness scale. In D.L. Worthington \& G.D. Bodie (Eds.), The Sourcebook of Listening Research: Methodology and Measures (pp. 516-521). New York: John Wiley \& Sons, Inc. doi: 10.1002/9781119102991.ch57 
Ross, L., Greene, D., \& House, P. (1977). The "false consensus effect": An egocentric bias in social perception and attribution processes. Journal of Experimental Social Psychology, 13(3), 279-301. https://doi.org/10.1016/0022-1031(77)90049-X

Rossignac-Milon, M., Bolger, N., Zee, K. S., Boothby, E. J., \& Higgins, E. T. (2020). Merged Minds: Generalized Shared Reality in Dyadic Relationships. Journal of Personality and Social Psychology. Advance online publication. http://dx.doi.org/10.1037/pspi0000266

Rusbult, C. E., \& Van Lange, P. A. (2003). Interdependence, interaction, and relationships. Annual review of psychology, 54(1), 351-375.

Shaver, P. R., \& Mikulincer, M. (2002). Attachment-related psychodynamics. Attachment \& Human Development, 4(2), 133-161. https://doi.org/10.1080/14616730210154171

Shaver, P. R., \& Mikulincer, M. (2007). Adult attachment strategies and the regulation of emotion. Handbook of emotion regulation, $446,465$.

Simpson, J. A., Kim, J. S., Fillo, J., Ickes, W., Rholes, W. S., Oriña, M. M., \& Winterheld, H. A. (2011). Attachment and the management of empathic accuracy in relationship-threatening situations. Personality and Social Psychology Bulletin, 37(2), 242-254.

Smith, E. R., \& Mackie, D. M. (2016). Representation and incorporation of close others' responses: The RICOR model of social influence. Personality and Social Psychology Review, 20(4), 311-331.

Stern, C., \& West, T. V. (2018). Assessing accuracy in close relationships research: A truth and bias approach. Journal of Social and Personal Relationships, 35(1), 89-111.

Stern, C., West, T. V., \& Schoenthaler, A. (2013). The dynamic relationship between accuracy and bias in social perception research. Social and Personality Psychology Compass, 7(5), 303-314.

Walsh, C. M., \& Neff, L. A. (2018). We're better when we blend: The benefits of couple identity fusion. Self and Identity, 17(5), 587-603.

West, T. V., \& Kenny, D. A. (2011). The truth and bias model of judgment. Psychological Review, 118(2), $357-378$. 


\section{Supplementary Information for:}

Perceptions and correspondence of climate change beliefs and behavior among romantic couples

Matthew H. Goldberg ${ }^{*}$, Cheryl L. Carmichael ${ }^{2,3}$, Karine Lacroix ${ }^{1}$, Abel Gustafson ${ }^{4}$, Seth A. Rosenthal ${ }^{1}$, and Anthony Leiserowitz ${ }^{1}$

${ }^{1}$ Yale Program on Climate Change Communication Yale University

${ }^{2}$ Department of Psychology Brooklyn College, City University of New York

${ }^{3}$ Department of Psychology Graduate Center, City University of New York

${ }^{4}$ Department of Communication University of Cincinnati

*Corresponding author: Matthew H. Goldberg, 205 Prospect street, New Haven, CT 06511. Email: matthew.goldberg@yale.edu 


\section{Supplementary Information}

Contents

Pages

Factor analyses

22-26

Additional analyses

27

Interaction tests

28-40

Models of individual items

41-49

All analyses with outliers included

50

Analyses by country

$51-53$ 


\section{Factor analyses}

In this section, we report exploratory factor analyses of four global warming indices: respondent's own global warming beliefs, respondent's own global warming behavior, perceived partner's global warming beliefs, and perceived partner's global warming behavior. Results are reported in Supplementary Tables 1-4. 
Supplementary Table 1

Factor analysis of person's own global warming beliefs using maximum likelihood

\begin{tabular}{lc}
\hline & $\begin{array}{c}\text { Factor } \\
\text { loadings }\end{array}$ \\
\hline Global warming is happening & 0.60 \\
Global warming is human caused & 0.48 \\
$\begin{array}{l}\text { I worry about global warming } \\
\text { The issue of global warming is important to me } \\
\text { personally }\end{array}$ & 0.83 \\
\hline
\end{tabular}


Supplementary Table 2

Factor analysis of person's own global warming behavior using maximum likelihood

\begin{tabular}{|c|c|}
\hline & $\begin{array}{l}\text { Factor } \\
\text { loadings }\end{array}$ \\
\hline Signed a petition that supports actions to reduce global warming & 0.77 \\
\hline Donated money to an organization working to reduce global warming & 0.59 \\
\hline Shared information about global warming on social media & 0.73 \\
\hline $\begin{array}{l}\text { Discussed the importance of global warming with friends or family } \\
\text { members }\end{array}$ & 0.65 \\
\hline
\end{tabular}


Supplementary Table 3

Factor analysis of perceived partner's global warming beliefs using maximum likelihood

Factor

loadings

Global warming is happening

0.56

Global warming is human caused

0.50

They worry about global warming

0.71

The issue of global warming is important to them personally 
Supplementary Table 4

Factor analysis of perceived partner's global warming behavior using maximum likelihood

Factor

loadings

Signed a petition that supports actions to reduce global warming

0.80

Donated money to an organization working to reduce global warming

Shared information about global warming on social media

0.71

Discussed the importance of global warming with friends or family members 


\section{Additional Analyses}

We found similar levels of correspondence between couples' perceptions of each other's global warming beliefs and behaviors (Supplementary Figure 1). We hypothesized that correspondence would be stronger for actual beliefs than perceived beliefs because we expected misperceptions of one's partner to be common-making actual beliefs more likely to have stronger correspondence. Results showed that correspondence of actual beliefs was marginally stronger than perceived partner beliefs (38\% vs. $32 \% ; Z=1.34, p=.090$; Figure 2, left panel), although this difference was small. We also hypothesized that, because behavior is relatively more observable than beliefs, there would be no difference in correspondence between behavior and perceived behavior. This is indeed what we found $(Z=-1.23, p=.216$; Supplementary Figure 1, right panel). However, it is important to note that the correspondence differences reported in the two hypothesis tests reported above are themselves not significantly different from each other.

Supplementary Figure 1

Correspondence of global warming beliefs and behavior among romantic couples

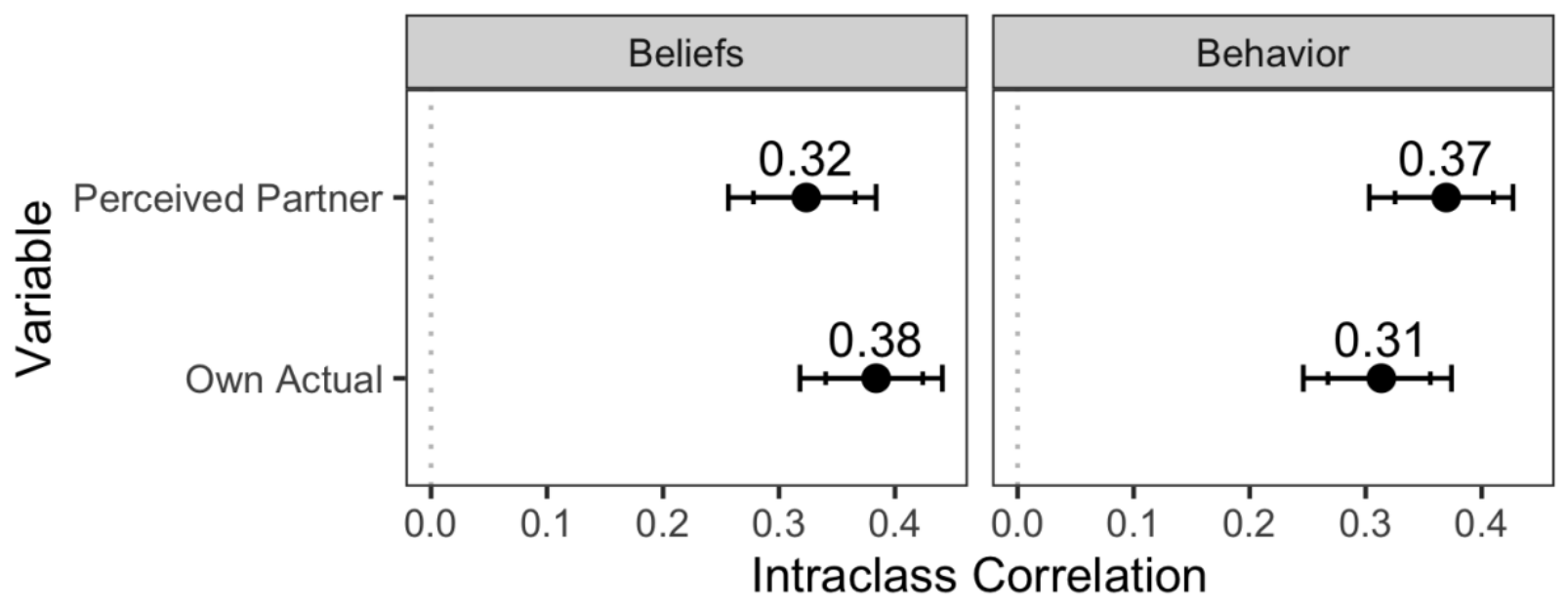

Note. The left panel displays correspondence between partners' perceptions of each other's beliefs (top row) and correspondence between partners' own global warming beliefs (bottom row). The right panel displays correspondence between perceptions of each other's behavior (top row) and between partner's own behavior (bottom row). Outside error bars represent bootstrap 95\% confidence intervals with 2,000 resamples. Inside error bars represent bootstrap 83\% confidence intervals with 2,000 resamples, which are plotted to aid visual comparisons of significant differences between coefficients at the $p=.05$ alpha level (Goldstein \& Healy, 1995). 


\section{Interaction Tests}

In this section, we report on tests of moderators of the relationship between partner's beliefs/behavior and perceptions of partner's beliefs/behavior. We preregistered the hypothesis that this relationship would be stronger among people who discuss global warming with their partner. Full model results are reported in Supplementary Tables 5 and 6.

We also tested six relationship-specific moderators. We applied a Bonferroni correction by dividing the original alpha level by the number of additional moderators tested $(.05 / 6=.008)$. We only examined interactions further and highlighted the results in the main text if they met or surpassed this stricter threshold. The moderators we tested were attachment security (anxiety and avoidance, in the same model), perceived partner responsiveness, relationship satisfaction, cohabitation, and relationship length. Full model results for these analyses are reported in Supplementary Tables 5-16. 
Supplementary Table 5

Model with interaction between partner's beliefs and global warming discussion predicting perceived partner beliefs

Dependent variable:

\section{Perceived Partner GW}

Beliefs

Own GW beliefs

Partner GW beliefs

Discussion

Partner GW

beliefs:Discussion

Constant
$0.29^{* * * *}$

$(0.25,0.34)$

$0.28^{* * *}$

$(0.19,0.38)$

$0.46^{* * *}$

$(0.33,0.58)$

$0.18^{* * *}$

$(0.08,0.28)$

$-0.41^{* * * *}$

$(-0.53,-0.29)$

Note. ${ }^{*} p<.05,{ }^{* *} p<.01,{ }^{* * * *} p<.001 . \mathrm{GW}=$ Global warming. Coefficients are standardized and $95 \%$ confidence intervals are shown in parentheses. 
Supplementary Table 6

Model with interaction between partner's behaviors and global warming discussion predicting perceived partner behaviors

Dependent variable:

Perceived Partner GW

Behavior

Own GW behavior

$0.46^{* * *}$

$(0.42,0.50)$

Partner GW behavior

$0.24^{* * *}$

$(0.13,0.35)$

Discussion

$0.15^{*}$

$(0.03,0.28)$

Partner GW

behavior:Discussion

$0.14^{*}$

$(0.02,0.26)$

Constant

$-0.14^{*}$

$(-0.26,-0.02)$

Note. ${ }^{*} p<.05,{ }^{* *} p<.01,{ }^{* * *} p<.001 . \mathrm{GW}=$ Global warming. Coefficients are standardized and $95 \%$ confidence intervals are shown in parentheses. 
Supplementary Table 7

Model with interaction between partner's beliefs and attachment avoidance/anxiety predicting perceived partner beliefs

Dependent variable:

Perceived Partner GW

Beliefs

Own GW beliefs

Partner GW beliefs

Avoidance

Anxiety

Partner GW

beliefs:Avoidance

Partner GW beliefs:Anxiety

Constant

$$
0.33^{* * *}
$$

$(0.29,0.37)$

$$
0.44^{* * *}
$$

$(0.40,0.49)$

$-0.03$

$(-0.07,0.02)$

$-0.06^{* *}$

$(-0.10,-0.02)$

$(-0.03,0.06)$

$$
-0.02
$$

$(-0.06,0.02)$

$-0.0002$

$(-0.04,0.03)$

Note. ${ }^{*} p<.05,{ }^{* *} p<.01,{ }^{* * *} p<.001 . \mathrm{GW}=$ Global warming. Coefficients are standardized and $95 \%$ confidence intervals are shown in parentheses. 
Supplementary Table 8

Model with interaction between partner's behavior and attachment avoidance/anxiety predicting perceived partner behavior

Dependent variable:

Perceived Partner GW

Behavior

Own GW behavior

$0.46^{\text {**** }}$

$(0.42,0.50)$

Partner GW behavior

$0.37^{* * *}$

$(0.33,0.41)$

Avoidance

0.01

$(-0.03,0.05)$

Anxiety

0.01

$(-0.04,0.05)$

Partner GW

behavior:Avoidance

$-0.01$

$(-0.05,0.04)$

Partner GW behavior:Anxiety

$0.06^{* *}$

$(0.02,0.10)$

Constant

$$
-0.01
$$

$(-0.04,0.03)$

Note. ${ }^{*} p<.05,{ }^{* *} p<.01,{ }^{* * *} p<.001 . \mathrm{GW}=$ Global warming. Coefficients are standardized and $95 \%$ confidence intervals are shown in parentheses. 
Supplementary Table 9

Model with interaction between partner's beliefs and perceived partner responsiveness predicting perceived partner beliefs

Dependent variable:

Perceived Partner GW

Beliefs

Own GW beliefs

Partner GW beliefs

PPR

Partner GW

beliefs:PPR

Constant
$(-0.06,0.01)$

$0.34^{* * * *}$

$(0.29,0.38)$

$0.43^{* * *}$

$(0.39,0.48)$

$0.12^{* * *}$

$(0.08,0.15)$

$-0.03$

0.001

$(-0.03,0.04)$

Note. ${ }^{*} p<.05,{ }^{* *} p<.01,{ }^{* * *} p<.001 . \mathrm{GW}=$ Global warming. PPR = Perceived partner responsiveness. Coefficients are standardized and 95\% confidence intervals are shown in parentheses. 
Supplementary Table 10

Model with interaction between partner's behavior and perceived partner responsiveness predicting perceived partner behavior

Dependent variable:

Perceived Partner GW

Behavior

Own GW behavior

$0.46^{\text {**** }}$

$(0.42,0.50)$

Partner GW behavior

$0.37^{* * * *}$

$(0.33,0.41)$

PPR

$$
0.05^{* *}
$$

$(0.02,0.09)$

Partner GW

behavior:PPR

0.002

$(-0.03,0.04)$

Constant

$$
-0.001
$$

$(-0.04,0.03)$

Note. ${ }^{*} p<.05,{ }^{* *} p<.01,{ }^{* * *} p<.001 . \mathrm{GW}=$ Global warming. PPR = Perceived partner responsiveness. Coefficients are standardized and 95\% confidence intervals are shown in parentheses. 
Supplementary Table 11

Model with interaction between partner's beliefs and relationship satisfaction predicting perceived partner beliefs

Dependent variable:

Perceived Partner GW

Beliefs

Own GW beliefs

Partner GW beliefs

Satisfaction

Partner GW

beliefs:Satisfaction

Constant

$0.33^{* * * *}$

$(0.29,0.38)$

$$
0.44^{* * * *}
$$

$(0.40,0.48)$

$0.08^{* * *}$

$(0.04,0.11)$

$-0.001$

$(-0.04,0.03)$

$-0.001$

$(-0.04,0.03)$

Note. ${ }^{*} p<.05,{ }^{* *} p<.01,{ }^{* * *} p<.001 . \mathrm{GW}=$ Global warming. Coefficients are standardized and $95 \%$ confidence intervals are shown in parentheses. 
Supplementary Table 12

Model with interaction between partner's behavior and relationship satisfaction predicting perceived partner behavior

Dependent variable:

Perceived Partner GW

Behavior

Own GW behavior

$0.46^{* * *}$

$(0.42,0.50)$

Partner GW behavior

$0.37^{* * *}$

$(0.33,0.41)$

Satisfaction

$$
0.04^{*}
$$

$(0.001,0.07)$

Partner GW

behavior:Satisfaction

$-0.03$

$(-0.06,0.01)$

Constant

$-0.001$

$(-0.03,0.03)$

Note. ${ }^{*} p<.05,{ }^{* *} p<.01,{ }^{* * * *} p<.001 . \mathrm{GW}=$ Global warming. Coefficients are standardized and $95 \%$ confidence intervals are shown in parentheses. 
Supplementary Table 13

Model with interaction between partner's beliefs and cohabitation predicting perceived partner beliefs

Dependent variable:

Perceived Partner GW

Beliefs

Own GW beliefs

Partner GW beliefs

Cohabitating

Partner GW

beliefs:Cohabitating

$0.33^{* * *}$

$(0.29,0.38)$

$0.40^{* * *}$

$(0.33,0.48)$

$-0.09^{*}$

$(-0.17,-0.01)$

Constant

\subsection{6}

$(-0.03,0.14)$

$0.07^{*}$

$(0.001,0.13)$

Note. ${ }^{*} p<.05,{ }^{* *} p<.01,{ }^{* * *} p<.001 . \mathrm{GW}=$ Global warming. Coefficients are standardized and $95 \%$ confidence intervals are shown in parentheses. 
Supplementary Table 14

Model with interaction between partner's behavior and cohabitation predicting perceived partner behavior

Dependent variable:

Perceived Partner GW

Behavior

Own GW behavior

$0.47^{* * *}$

$(0.43,0.51)$

Partner GW behavior

$$
0.36^{* * *}
$$

$(0.29,0.42)$

Cohabitating

$$
\begin{gathered}
0.02 \\
(-0.06,0.09)
\end{gathered}
$$

Partner GW

behavior:Cohabitating

$$
0.02
$$

$(-0.06,0.10)$

Constant

$-0.01$

$(-0.07,0.05)$

Note. ${ }^{*} p<.05,{ }^{* *} p<.01,{ }^{* * *} p<.001 . \mathrm{GW}=$ Global warming. Coefficients are standardized and $95 \%$ confidence intervals are shown in parentheses. 
Supplementary Table 15

Model with interaction between partner's beliefs and relationship length predicting perceived partner beliefs

Dependent variable:

Perceived Partner GW

Beliefs

Own GW beliefs

Partner GW beliefs

Relationship Length

Partner GW beliefs:Relationship

Length

Constant
$0.34^{* * * *}$

$(0.29,0.38)$

$0.44^{* * *}$

$(0.40,0.49)$

$-0.003$

$(-0.04,0.03)$

0.03

$(-0.005,0.07)$

0.0003

$(-0.03,0.04)$

Note. ${ }^{*} p<.05,{ }^{* *} p<.01,{ }^{* * * *} p<.001 . \mathrm{GW}=$ Global warming. Coefficients are standardized and $95 \%$ confidence intervals are shown in parentheses. 
Supplementary Table 16

Model with interaction between partner's behavior and relationship length predicting perceived partner behavior

Dependent variable:

Perceived Partner GW

Behavior

Own GW behavior

Partner GW behavior

Relationship Length

Partner GW behavior:Relationship

Length

Constant

$0.47^{* * *}$

$(0.43,0.51)$

$0.37^{* * *}$

$(0.33,0.41)$

0.03

$(-0.01,0.06)$

0.02

$(-0.01,0.06)$

0.003

$(-0.03,0.04)$

Note. ${ }^{*} p<.05,{ }^{* *} p<.01,{ }^{* * *} p<.001 . \mathrm{GW}=$ Global warming. Coefficients are standardized and $95 \%$ confidence intervals are shown in parentheses. 


\section{Models of Individual Items}

In the main text, we report on findings from the global warming belief and behavior indices, each of which are composed of four items. In this section, we report on the same models in the main text on each individual item. Full model results are reported in Supplementary Tables 17-24. 
Supplementary Table 17

Model predicting perceived partner beliefs about whether global warming is happening

\begin{tabular}{lc}
\hline & Dependent variable: \\
\cline { 2 - 2 } & $\begin{array}{c}\text { Perceived Partner GW } \\
\text { Happening }\end{array}$ \\
\hline Own GW Happening & $0.37^{* * *}$ \\
& $(0.33,0.42)$ \\
Partner GW & $0.35^{* * *}$ \\
Happening & $(0.31,0.40)$ \\
Constant & 0.00 \\
& $(-0.04,0.04)$ \\
\hline
\end{tabular}

Note. ${ }^{*} p<.05,{ }^{* *} p<.01,{ }^{* * *} p<.001 . \mathrm{GW}=$ Global warming. Coefficients are standardized and $95 \%$ confidence intervals are shown in parentheses. 
Supplementary Table 18

Model predicting perceived partner beliefs about whether global warming is humancaused

Dependent variable:

Perceived Partner GW Human-

Caused

Own GW Human-Caused

$0.40^{* * *}$

$$
(0.35,0.44)
$$

Partner GW Human-

Caused

$$
0.23^{* * *}
$$

$(0.19,0.28)$

Constant

$$
0.00
$$

$(-0.04,0.04)$

Note. ${ }^{*} p<.05,{ }^{* *} p<.01,{ }^{* * *} p<.001 . \mathrm{GW}=$ Global warming. Coefficients are standardized and $95 \%$ confidence intervals are shown in parentheses. 
Supplementary Table 19

Model predicting perceptions of whether partner is worried about global warming

\begin{tabular}{lc}
\hline & Dependent variable: \\
\cline { 2 - 2 } & $\begin{array}{c}\text { Perceived Partner GW Human- } \\
\text { Caused }\end{array}$ \\
\hline Own GW Worry & $0.32^{* * *}$ \\
& $(0.27,0.36)$ \\
Partner GW & $0.38^{* * *}$ \\
Worry & $(0.34,0.42)$ \\
& 0.00 \\
Constant & $(-0.04,0.04)$ \\
\hline
\end{tabular}

Note. ${ }^{*} p<.05,{ }^{* *} p<.01,{ }^{* * *} p<.001 . \mathrm{GW}=$ Global warming. Coefficients are standardized and $95 \%$ confidence intervals are shown in parentheses. 
Supplementary Table 20

Model predicting perceptions of partner beliefs about the personal importance of global warming

Dependent variable:

Perceived Partner GW

Importance

Own GW Importance

$0.36^{* * * *}$

$(0.32,0.40)$

Partner GW

Importance

$0.36^{* * *}$

$(0.32,0.40)$

Constant

$-0.00$

$(-0.04,0.04)$

Note. ${ }^{*} p<.05,{ }^{* *} p<.01,{ }^{* * *} p<.001 . \mathrm{GW}=$ Global warming. Coefficients are standardized and $95 \%$ confidence intervals are shown in parentheses. 
Supplementary Table 21

Model predicting perceptions of how often partner signs petitions supporting action on global warming

Dependent variable:

Perceived Partner

Petition

Own Petition

$$
0.44^{* * *}
$$

$(0.40,0.48)$

Partner

Petition

$$
0.30^{* * *}
$$

$(0.26,0.34)$

Constant

$-0.00$

$(-0.04,0.04)$

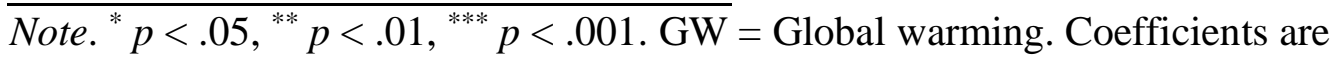
standardized and $95 \%$ confidence intervals are shown in parentheses. 
Supplementary Table 22

Model predicting perceptions of how often partner donates to organizations working to reduce global warming

\begin{tabular}{lc}
\hline & \begin{tabular}{c} 
Dependent variable: \\
\cline { 2 - 2 }
\end{tabular} \\
\cline { 2 - 2 } & $\begin{array}{c}\text { Perceived Partner } \\
\text { Donate }\end{array}$ \\
\hline Own Donate & $0.44^{* * *}$ \\
& $(0.40,0.49)$ \\
Partner & $0.28^{* * *}$ \\
Donate & $(0.24,0.32)$ \\
& 0.00 \\
Constant & $(-0.04,0.04)$ \\
& \\
\hline
\end{tabular}

Note. ${ }^{*} p<.05,{ }^{* *} p<.01,{ }^{* * *} p<.001 . \mathrm{GW}=$ Global warming. Coefficients are standardized and $95 \%$ confidence intervals are shown in parentheses. 
Supplementary Table 23

Model predicting perceptions of how often partner shares information about global warming on social media

Dependent variable:

Perceived Partner Share
Info.

Own Share Info.

$$
0.38^{* * *}
$$

$(0.33,0.42)$

Partner Share

Info.

$$
0.35^{* * *}
$$

$$
(0.31,0.40)
$$

Constant

$$
-0.00
$$

$$
(-0.04,0.04)
$$

Note. ${ }^{*} p<.05,{ }^{* *} p<.01,{ }^{* * *} p<.001 . \mathrm{GW}=$ Global warming. Info. = Information. Coefficients are standardized and 95\% confidence intervals are shown in parentheses. 
Supplementary Table 24

Model predicting perceptions of how often partner discusses the importance of global warming with friends and family members

Dependent variable:

Perceived Partner Discuss

Friends/Family

Own Discuss Friends/Family

Partner Discuss

Friends/Family

Constant
$0.48^{* * *}$

$(0.43,0.52)$

$(0.25,0.34)$

$-0.00$

$(-0.04,0.04)$

$\overline{\text { Note. }}{ }^{*} p<.05,{ }^{* *} p<.01,{ }^{* * *} p<.001 . \mathrm{GW}=$ Global warming. Coefficients are standardized and 95\% confidence intervals are shown in parentheses. 


\section{All Analyses with Outliers Included}

We preregistered the criterion that outliers - defined as falling $-/+3$ standard deviations from the mean on the global warming beliefs and behavior indices - would be removed from analyses. However, interested readers might want to know if results substantively change when outliers are included in the analyses. We have reproduced all analyses on the sample with outliers included and have posted this document on our Open Science Framework project page. The file is named couples_analysis_code_retain_outliers.html, which is available for download at https://osf.io/aup7n/. 


\section{Analyses by Country}

To ensure we reached our goal sample size, we did not place any geographic restrictions when recruiting respondents. Thus, anyone on the Prolific platform could participate in this study. All study materials were in English. Respondents from 29 countries participated. Majority of the respondents $(53 \%)$ were from either the United Kingdom $(n=471)$, United States $(n=221)$, or Portugal $(n=117)$. Country of residence was unknown for $14 \%(n=214)$ of respondents.

For exploratory purposes, we ran Actor-Partner Interdependence Model analyses with random intercepts for couples and random effects with individual-level variables nested within countries. Results for most countries are extremely uncertain and unstable because of small sample sizes within most countries. However, for countries for which we have a reasonable sample size (United Kingdom, United States, Portugal), results show strong consistency across countries for belief and behavior dependent variables (Supplementary Figures 2-3). 


\section{Supplementary Figure 2}

Assumed similarity (left panel) and accuracy (right panel) effects for global warming beliefs, by country
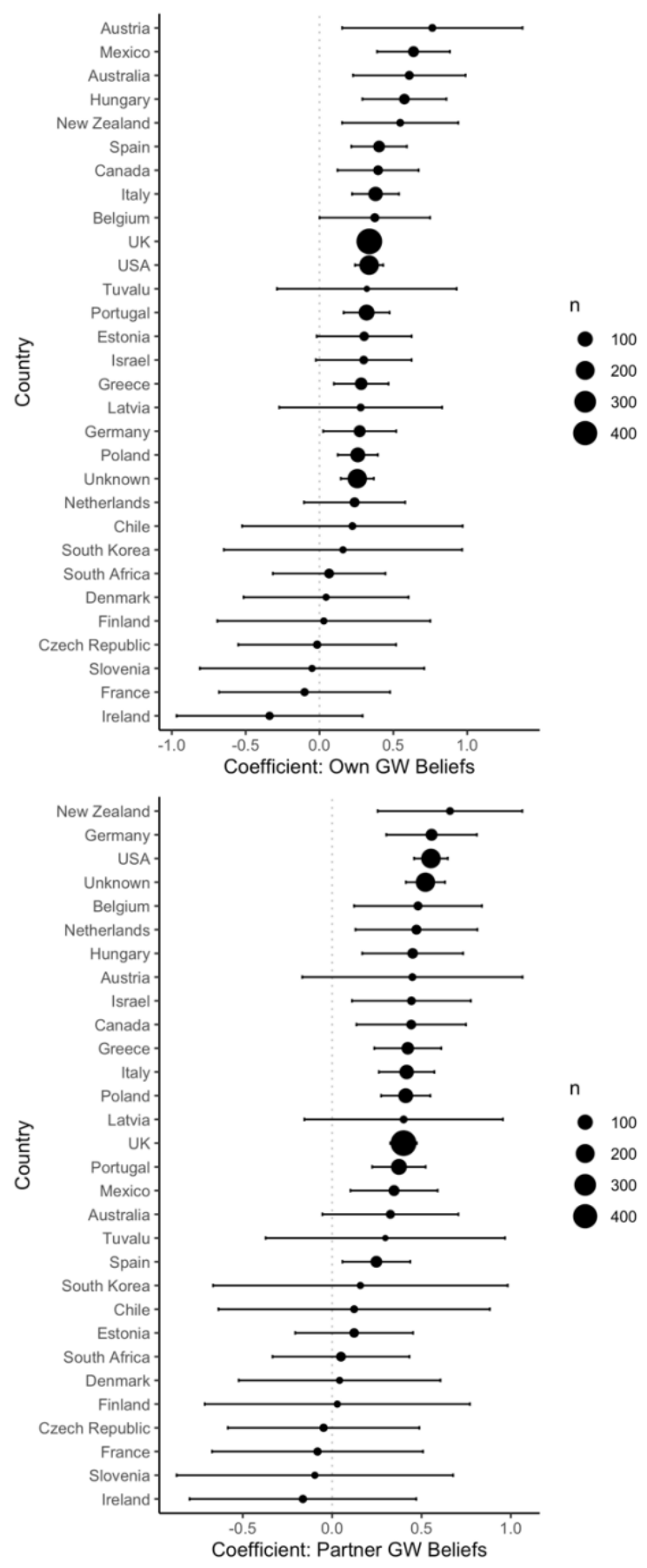
Supplementary Figure 3

Assumed similarity (left panel) and accuracy (right panel) effects for global warming behavior, by country
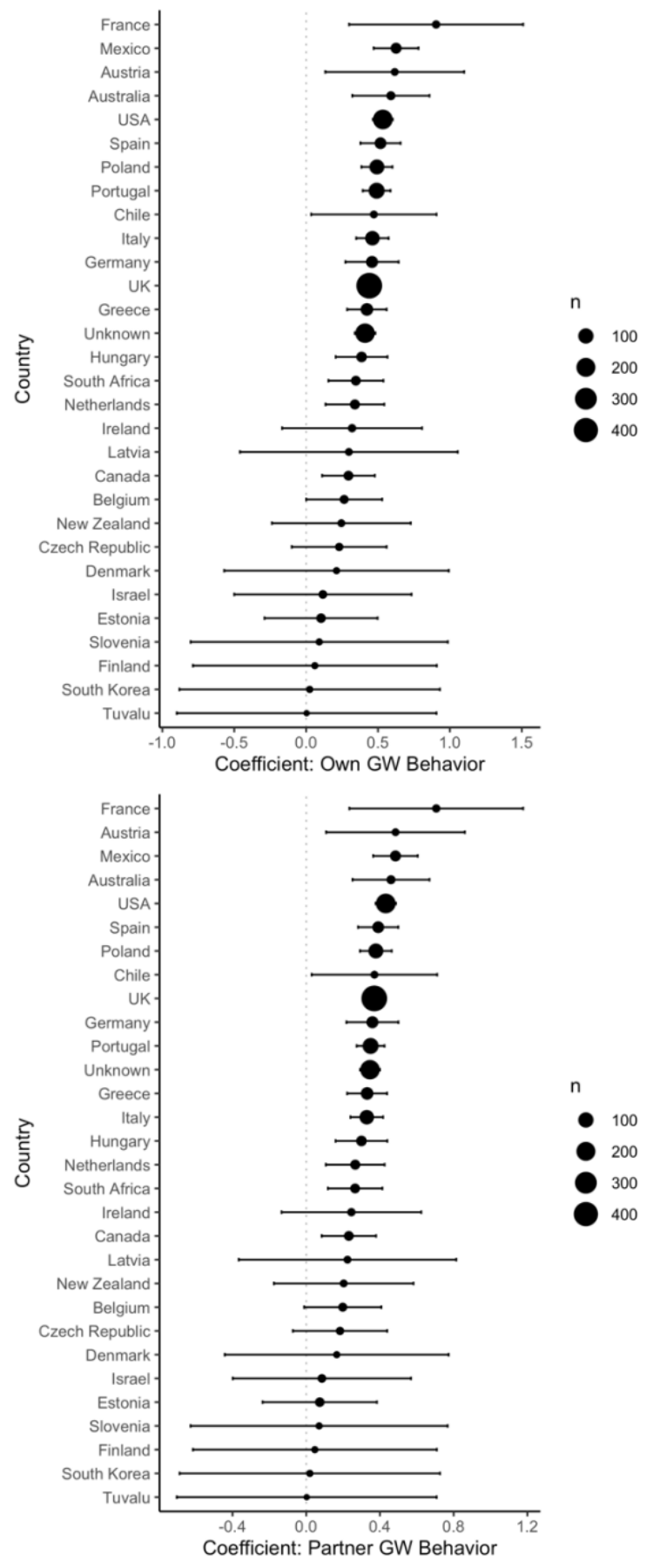